\title{
Novel design and performance enhancement of domestic refrigerators with thermal storage
}

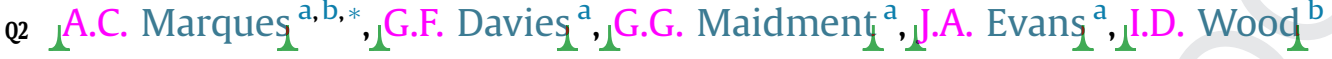 \\ ${ }^{a}$ Department of Urban Engineering, London South Bank University, 103 Borough Road, London SE1 OAA, UK \\ ${ }^{\mathrm{b}}$ Adande Refrigeration, 45 Pinbush Road, South Lowestoft Industrial Estate, Lowestoft, Suffolk NR33 7NL, UK
}

\section{H I G H L I G H T S}

- The design/operation of a household thermal storage refrigerator was investigated.

- Demonstrated that single speed compressor efficiency increases with displacement.

- The additional cooling capacity of larger compressors can be accumulated in a PCM.

- Integration of a PCM into the refrigerator allows for an extended off-cycle period.

- Combination of large compressors and PCMs enhances overall refrigerator efficiency.

\section{A R T I C L E I N F O}

\section{Article history:}

Received 9 May 2013

Accepted 19 November 2013

Available online $\mathrm{xxx}$

\section{Keywords:}

Household refrigerator

Phase change material

Energy storage

Compressor

Energy efficiency

\begin{abstract}
A B S T R A C T
This paper investigates the design and operation of a thermal storage refrigerator. Firstly, compressor performance at a range of typical refrigerator operating conditions was analysed. The model results suggest that larger compressors are more efficient when running, with isentropic efficiency increasing by $50 \%$ as the displacement increased from 4 to $8 \mathrm{~cm}^{3}$. The impact of compressor performance on the overall refrigerator efficiency was estimated and the results indicated that an energy reduction of $19.5 \%$ can be obtained by replacing a conventionally sized, $4 \mathrm{~cm}^{3}$ compressor by a larger $8 \mathrm{~cm}^{3}$ model. However, using a larger compressor will normally lead to more start/stop events, which reduces overall efficiency. A method is proposed for exploiting the superior performance of large compressors by accumulating their high cooling capacity output in a phase change material (PCM), reducing the number of on/off cycles. Numerical modelling and experimental validation were undertaken using a prototype thermal storage refrigerator, incorporating a PCM, to estimate the PCM charge and discharge rate and the corresponding refrigerator on and off cycle durations at different ambient conditions. The results showed that the integration of a $5 \mathrm{~mm}$ PCM slab into the refrigerator allowed for $3-^{5} \mathrm{~h}$ of continuous operation without a power supply. The numerical model was found to be in good agreement with the experimental results, with the error between the simulation and tests below $5 \%$ for most experiments.
\end{abstract}

(c) 2013 Published by Elsevier Ltd.

\section{Introduction}

A growing global environmental awareness and the rising costs of energy are driving the demand for the development of sustainable cooling technologies. It is estimated that refrigeration and

Abbreviations: ASHRAE, American Society of Heating, Refrigerating and Air Conditioning Engineers; COP, coefficient of performance; GHG, greenhouse gases; PCM, phase change material; SLHE, suction line heat exchanger; VIP, vacuum insulated panel; VCS, variable speed compressor.

* Corresponding author. Department of Urban Engineering, London South Bank University, 103 Borough Road, London SE1 OAA, UK. Tel.: +44 1502576716; fax: +44 1502533794.

E-mail address: marquesc@lsbu.ac.uk (A.C. Marques). air-conditioning are responsible for $15 \%$ of the global electricity consumption [1]. There are approximately 1 billion domestic refrigerators in use worldwide [2], and although their direct GHG emissions have been greatly reduced by the introduction of hydrocarbon refrigerants, their indirect emissions remain very high due to the electricity input needed for operation of the refrigerator. Most governments have implemented minimum energy performance standards for household refrigerators and energy labelling programs to regulate the market and drive the search for innovative solutions, to further improve the efficiency of these appliances.

The energy consumption of refrigerators is affected by the efficiency of their components, ambient temperature, product loading, number of door openings, thermostat setting position and refrigerant migration during the compressor off-cycle. The main load to 


\begin{tabular}{|c|c|c|c|}
\hline \multicolumn{2}{|c|}{ Nomenclature } & $U$ & global heat transfer coefficient $\left(\mathrm{W} \mathrm{m}{ }^{-2} \mathrm{~K}^{-1}\right)$ \\
\hline$A$ & surface area $\left(\mathrm{m}^{2}\right)$ & $y$ & distance through PCM from bottom surface (m) \\
\hline$A_{\mathrm{L}}$ & area of layer $\left(\mathrm{m}^{2}\right)$ & \multicolumn{2}{|c|}{ Greek symbols } \\
\hline$B$ & PCM thickness (m) & $\alpha$ & thermal diffusivity $\left(\mathrm{m}^{2} \mathrm{~s}^{-1}\right)$ \\
\hline$c p$ & specific heat $\left(\mathrm{J} \mathrm{kg}^{-1} \mathrm{~K}^{-1}\right)$ & $\lambda$ & latent heat of fusion $\left(\mathrm{J} \mathrm{kg}^{-1}\right)$ \\
\hline$\Delta t$ & time step $(\mathrm{s})$ & $\rho$ & density $\left(\mathrm{kg} \mathrm{m}^{-3}\right)$ \\
\hline$\Delta T$ & temperature difference $(\mathrm{K})$ & & \\
\hline$\Delta y$ & layer thickness (m) & \multicolumn{2}{|c|}{ Subscripts } \\
\hline$H$ & enthalpy change $(\mathrm{J})$ & liq & liquid \\
\hline$k$ & thermal conductivity $\left(\mathrm{W} \mathrm{m} \mathrm{m}^{-1} \mathrm{~K}^{-1}\right)$ & mel & melting point \\
\hline$L_{\mathrm{f}}$ & liquid fraction & $\mathrm{N}$ & node point at north of point $\mathrm{P}$ \\
\hline$m_{\mathrm{L}}$ & mass of layer $(\mathrm{kg})$ & $\mathrm{P}$ & point $\mathrm{P}$ \\
\hline Qevapor & or cooling capacity (W) & S & node point at south of point $P$ \\
\hline$Q_{\text {fridge }}$ & refrigerator heat gain $(\mathrm{W})$ & sol & solid \\
\hline$s$ & solid $\rightarrow$ liquid interface & & \\
\hline$T$ & temperature $(\mathrm{K})$ & \multicolumn{2}{|c|}{ Superscripts } \\
\hline$t$ & time $(\mathrm{s})$ & $i$ & iteration \\
\hline
\end{tabular}

the cabinet results from conduction through the cabinet walls and consequently by replacing the standard polyurethane foam insulation with vacuum insulated panels (VIPs), energy savings of up to $25 \%$ can be achieved [3]. Door openings also introduce heat gains into the refrigerator compartment due to heat transfer to interior surfaces and air exchange with the exterior ambient air. The energy consumption of a refrigerator-freezer with door openings (one opening every $40 \mathrm{~min}$ for the freezer and one every $12 \mathrm{~min}$ for the refrigerator over a $10 \mathrm{~h}$ period) was found to increase by $10 \%$ compared to the same product without door openings [4]. The significant influence of thermostat setting position has been demonstrated experimentally and suggests that a $1{ }^{\circ} \mathrm{C}$ reduction in the freezer temperature can result in a $7.8 \%$ increase in energy consumption [5]. In addition, the losses resulting from refrigerant charge displacements e.g. due to off-cycle migration and on-cycle redistribution, were estimated to be $11 \%$ (in capacity) and $9 \%$ (in energy efficiency) [6]. However, the energy loss due to refrigerant charge displacement can be prevented by fitting a liquid line solenoid valve to stop refrigerant migration from the condenser to the evaporator during the compressor off-cycle.

The compressor is responsible for more than $80 \%$ of the total energy consumed by the refrigerator. Energy savings of up to $40 \%$ are possible by replacing a standard single speed compressor by a variable speed compressor (VSC), which adjusts the refrigeration capacity in relation to the load [7]. Both VIPs and VSCs are very promising technologies, however they are also very expensive, which limits their application to premium appliances only.

Phase change materials (PCMs) are substances with high latent heat content that freeze and melt at a nearly constant temperature, accumulating or releasing large amounts of energy during the process. The application of PCMs in domestic refrigerators is a novel solution with the potential to improve the appliance efficiency. The cooling energy stored in the PCM can be used to cool the compartment, increasing the refrigerator energetic autonomy, while the power supply is switched off. This approach was taken by Azzouz et al. [8], who tested a domestic refrigerator with $5 \times 10^{-3}$ and $10 \times 10^{-3} \mathrm{~m}$ (i.e. 5 and $10 \mathrm{~mm}$ ) ice slabs in contact with the evaporator surface. Their results showed that the time for which the refrigerator could be operated without power supply increased by up to 5 and $9 \mathrm{~h}$ respectively, depending on the thermal load. It was observed however, that only $60 \%$ of the $10 \mathrm{~mm}$ slab was frozen when the compressor switched off during the tests, probably due to the low thermal conductivity of the PCM, and/or the low cooling capacity of the $5 \times 10^{-6} \mathrm{~m}^{3}$ (i.e. $5 \mathrm{~cm}^{3}$ ) swept volume compressor employed.

In the next section of the current paper, it is demonstrated that for current single speed compressors efficiency increases with the compressor size. The impact of compressor selection on conventional refrigerators' energy consumption and running time is also demonstrated. However, high efficiency is only achieved when the compressor is running, and frequent on/off cycling of the compressor will reduce the overall efficiency. An effective way to exploit the higher performance of large compressors is to accumulate their excess cooling capacity in a PCM, thereby extending the length of the on and off cycle periods and minimizing the number of cycles per unit time.

The remainder of the paper describes a numerical and experimental investigation of the heat release and storage rate of encapsulated ice, which was used as the thermal energy storage material (i.e. PCM) in the refrigerator. The mathematical model used to predict the heat transfer during the phase change is based on the enthalpy method [9], with the governing equations discretized on a fixed grid using the finite difference method. The influence of PCM thickness (2, 3, 4 and $5 \mathrm{~mm}$ slabs) and ambient temperature $\left(20{ }^{\circ} \mathrm{C}, 25{ }^{\circ} \mathrm{C}, 30^{\circ} \mathrm{C}\right)$ and evaporating temperature $\left(-15{ }^{\circ} \mathrm{C}\right.$ and $\left.-10{ }^{\circ} \mathrm{C}\right)$ have been investigated numerically. The numerical model was validated experimentally at two ambient conditions using a test rig specifically designed for that purpose. The test rig consisted on a prototype refrigerator, fitted with a $5 \mathrm{~mm}$ PCM slab, which was cooled by an external coolant system.

\section{Compressor size and efficiency}

In the design of energy efficient domestic refrigerators it is important both to incorporate novel, energy efficient solutions, e.g. PCMs, and to combine them in the most efficient way with other components. This section considers the performance for different sizes of single speed compressors, which is a key component influencing refrigerator efficiency.

Compressor manufacturer datasheets provide information on compressor performance under ASHRAE conditions [10], i.e. a condensing temperature of $54.4^{\circ} \mathrm{C}$, and ambient, liquid and suction gas temperatures of $32.2^{\circ} \mathrm{C}$. These operating conditions are quite different from those obtained when the compressor is part of a domestic refrigeration system. Therefore, compressor performance under ASHRAE conditions may not reflect how well compressors will perform under more realistic conditions e.g. at ambient 
conditions normally found in domestic refrigeration. For example, the annual average room temperature is well below $32{ }^{\circ} \mathrm{C}$ and the suction temperature during typical operation of a refrigerator is normally much lower than $32{ }^{\circ} \mathrm{C}$. At lower ambient temperatures the compressor COP is higher as the pressure ratio will decrease due to a lower condensing temperature (providing that the same evaporating temperature is maintained).

Compressor performance can be evaluated by its isentropic efficiency, which compares the actual compressor energy consumption with the energy necessary for an ideal (i.e. reversible and adiabatic) compression process. The isentropic efficiency varies between 0 and 1 . An analysis of the compressor performance for different displacements (i.e. compressor sizes) was carried out, to compare isentropic efficiencies under typical refrigerator operating conditions. The $\mathrm{RS}+3$ compressor unit selection tool program developed by Danfoss [11] was used to predict performance data for each compressor displacement for typical domestic refrigerator operating conditions, i.e. condensing temperature of $35^{\circ} \mathrm{C}$, ambient temperature of $25^{\circ} \mathrm{C}$, evaporator superheat of $1 \mathrm{~K}$ and compressor suction temperature of $15{ }^{\circ} \mathrm{C}$, and assuming a suction line heat exchanger (SLHE) efficiency of 65\% [12].The CoolPack software, version 1.46 [13] was then used to calculate the compressor isentropic efficiency for each compressor size at a range of evaporating temperatures (from $-35^{\circ} \mathrm{C}$ to $-10^{\circ} \mathrm{C}$ ). The input data used in the program (cooling capacity, power consumption and COP) were obtained from the $\mathrm{RS}+3$ program. A more detailed description of this analysis can be found in Marques et al. [14]. The isentropic efficiency and cooling capacity for a range of compressor displacements is shown in Figs. 1 and 2 respectively.

As can be seen in Fig. 1, in general larger compressors are more efficient, with the isentropic efficiency increasing from 0.4 to 0.6 as the displacement increased from 4 to $8 \mathrm{~cm}^{3}$. The isentropic efficiency appeared to reach a maximum at a displacement of $8 \mathrm{~cm}^{3}$ and thereafter stayed the same or decreased slightly, although, the volumetric efficiency increased proportionally with displacement, for all of the compressor sizes evaluated. Therefore, the $8 \mathrm{~cm}^{3}$ compressor was the most efficient size amongst the compressors considered, for typical domestic refrigerator chilled storage conditions. Fig. 2 shows that the cooling capacity also increases proportionally with compressor displacement.

\section{Comparison of compressor sizes in a conventional domestic refrigerator}

Calculations were undertaken for a static conventional refrigerator to establish the impact of compressor selection on the overall

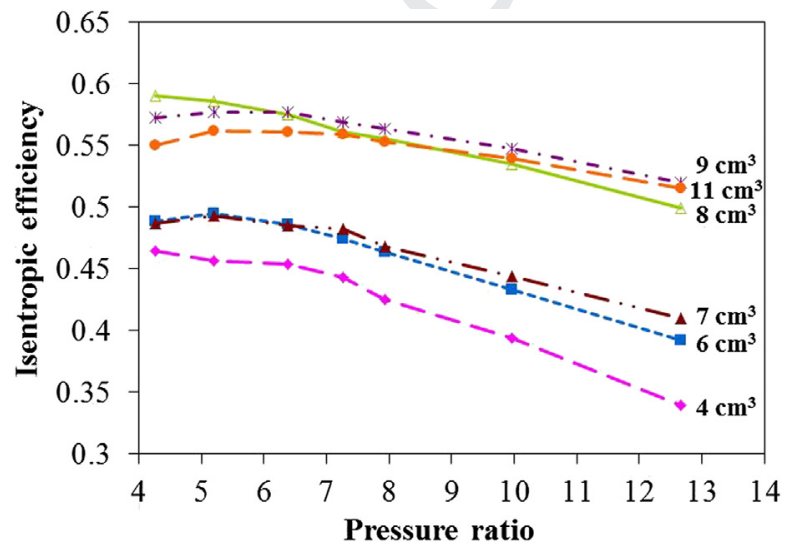

Fig. 1. Isentropic efficiency for different compressor displacements.

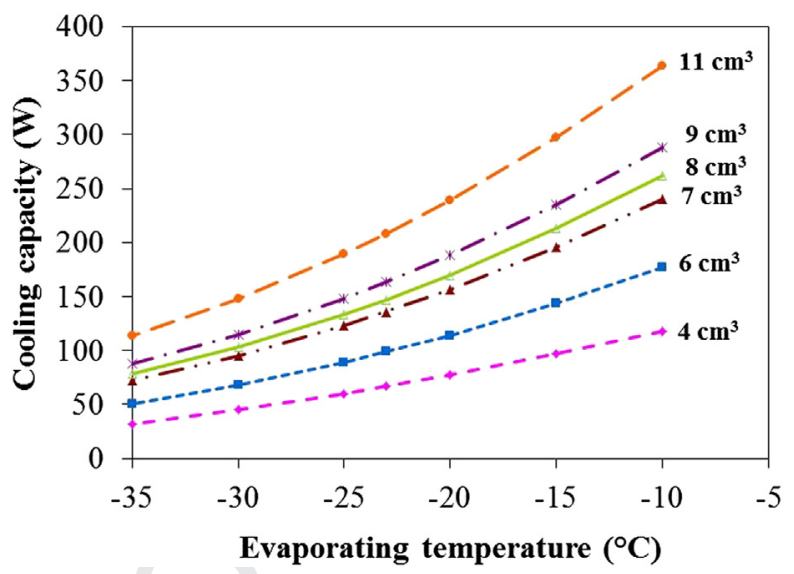

Fig. 2. Cooling capacity for different compressor displacements.

system performance. The refrigerator efficiency was evaluated in terms of total energy consumption and running time of the appliance. The running time was estimated from the heat load into the refrigerator compartment calculated as described below and the cooling capacity of the compressor, based on the data reported in Fig. 2.

The heat load into a conventionally sized under-counter refrigerator of internal dimensions $0.75 \times 0.45 \times 0.46 \mathrm{~m}$ was calculated by considering a steady state heat gain and then by adding an additional gain of $10 \%$ to account for real usage operation i.e. periods of door openings and introduction of warm food into the compartment. The ambient temperature was assumed to be $25^{\circ} \mathrm{C}$, which corresponds to the test temperature of the European Standard EN 153 [15] for subtropical refrigerators. It was considered that the back wall of the refrigerator would be warmer than the side walls and door due to the condenser being mounted on this wall. The condenser temperature was assumed to be $35{ }^{\circ} \mathrm{C}$. Additional heat from the compressor compartment was assumed to provide an extra $7.5^{\circ} \mathrm{C}$ to the bottom surface of the refrigerator. The compartment design temperature was $5{ }^{\circ} \mathrm{C}$ and as a baseline, an evaporating temperature of $-10{ }^{\circ} \mathrm{C}$ was considered. The three mechanisms of heat transfer, conduction, convection and radiation were considered in the heat load to the refrigerated compartment. These were combined in the form of a global heat transfer coefficient $(U)$ and the heat load into the refrigerator was then calculated using Equation (1).

$Q_{\text {fridge }}=U A \Delta T$

The heat load at $25{ }^{\circ} \mathrm{C}$ was estimated to be $23.8 \mathrm{~W}$. Table 1 presents the overall refrigerator performance with the different compressor displacements evaluated in Section 2.

Table 1

Static refrigerator performance with different compressor displacements.

\begin{tabular}{llllll}
\hline $\begin{array}{l}\text { Compressor } \\
\text { model }\end{array}$ & $\begin{array}{l}\text { Displacement } \\
\left(\mathrm{cm}^{3}\right)\end{array}$ & $\begin{array}{l}\text { Run } \\
\text { time (\%) }\end{array}$ & $\begin{array}{l}\text { Energy } \\
\text { consumption } \\
\text { (kWh/year) }\end{array}$ & $\begin{array}{l}\text { Cooling } \\
\text { capacity (W) }\end{array}$ & COP \\
\hline 1 & 4.0 & $22 \%$ & 92.2 & 110 & 2.26 \\
2 & 5.7 & $14 \%$ & 87.2 & 166 & 2.39 \\
3 & 7.48 & $11 \%$ & 87.2 & 225 & 2.39 \\
4 & 8.05 & $10 \%$ & 74.2 & 246 & 2.81 \\
5 & 8.76 & $9 \%$ & 76.1 & 272 & 2.74 \\
6 & 11.2 & $7 \%$ & 78.7 & 344 & 2.65 \\
\hline
\end{tabular}


As can be seen in Table 1 , the $8 \mathrm{~cm}^{3}$ compressor was optimal for the refrigerator specified above under typical operating conditions. An energy reduction of $19.5 \%$ was predicted by replacing the smaller $4 \mathrm{~cm}^{3}$ compressor by an $8 \mathrm{~cm}^{3}$ model and the run time decreased from $22 \%$ to $10 \%$. Since the run time of the appliance decreases as the compressor displacement increases the time required to cool the compartment becomes very short but the compressor needs to be used more frequently.

In order to fully exploit the higher performance of large compressors it is necessary to apply them in a novel way so that their excess cooling capacity is used effectively in cooling the refrigerator compartment. This can be achieved by storing cooling energy in a PCM. This results in the number of start/stop operations of the compressor being reduced and the overall energetic autonomy (i.e. off-cycle length) of the refrigerator being increased. The accumulated thermal energy can also improve the compartment temperature stability when the heat load suddenly increases e.g. during intense periods of door openings or product loading.

\section{PCM heat release and storage rate model}

Phase change processes are transient in nature as the temperature within the material varies with time and position. During the melting and solidification processes the solid/liquid interface moves according to the rate at which latent heat is absorbed or lost at the boundary. As a result the position of the boundary at any particular time during melting or solidification is not known and has to be determined as part of the solution for any phase change model [16].

\subsection{Mathematical formulation}

The PCM employed for the experimental tests (and simulated in the model) was water. The top surface of the water container was placed in thermal contact with the refrigerator evaporator, while the bottom surface of the enclosure was subjected to natural convection from the refrigerator compartment. To simplify the model, the side walls of the PCM container were assumed to be insulated, and therefore heat transfer within the PCM was treated as one dimensional. The following assumptions were also adopted to simplify the mathematical model:

1. Constant thermophysical properties for the PCM (e.g. thermal conductivity and specific heat), although different values were assumed for each phase;

2. The interface thickness was assumed to be zero with a sharp front separating both phases;

3. Constant latent heat, which was released or absorbed at a fixed phase change temperature;

4. Constant density for both phases;

5. The convection in the melted regions was neglected;

6. Supercooling effects were assumed to be non-existent;

7. The PCM container walls were assumed to be very thin and to have a negligible effect on the rate of heat transfer between the refrigerated compartment and the PCM;

8. It was assumed that conduction was the only heat transfer mechanism occurring inside the PCM.

The conservation of energy in the solid and liquid phases is described by differential Equation (2).

$$
\begin{aligned}
\frac{\partial T}{\partial t} & =\alpha \frac{\partial^{2} T}{\partial y^{2}} \quad, \text { where } \alpha=\alpha_{\text {sol }} \text { for } 0<y<s(t), t>0 ; \text { and } \\
\alpha & =\alpha_{\text {liq }} \text { for } s(t)<y<B, t>0
\end{aligned}
$$

The energy balance at the interface is obtained from Equation (3).

$\rho \lambda \frac{\partial s}{\partial t}=k_{\mathrm{sol}} \frac{\partial T}{\partial y}-k_{\mathrm{liq}} \frac{\partial T}{\partial y} \quad$ at $y=s(t), t>0$

The heat load was applied to the bottom surface of the PCM $(y=0)$ as a boundary condition. This heat load $\left(Q_{\text {fridge }}\right)$ was calculated as indicated in Section 3. At the top surface boundary $(y=B)$ a cooling capacity $\left(Q_{\text {evaporator }}\right)$ was applied during the freezing process. This cooling capacity was estimated for an $8 \mathrm{~cm}^{3}$ compressor model evaporating at $-10{ }^{\circ} \mathrm{C}$, using CoolPack [13]. The $8 \mathrm{~cm}^{3}$ compressor was identified (in Sections 2 and 3 ) as the most efficient model for the standard refrigerated storage conditions, to be simulated. It was assumed that the PCM was initially completely solid at a temperature of $0^{\circ} \mathrm{C}$, and all of the PCM (both solid and liquid) continued at this temperature during the melting process. The PCM was assumed to be in thermal equilibrium with the refrigerator air at the beginning of the freezing cycle, therefore the PCM was initially all liquid at $5{ }^{\circ} \mathrm{C}$, but its temperature was reduced to $0{ }^{\circ} \mathrm{C}$ before the phase change process started.

\subsection{Numerical solution}

The algebraic approximations normally used to solve differential Equations (2) and (3) require the phase change boundary to be tracked within the PCM volume. The enthalpy method was applied to simplify the problem as it eliminates the necessity to trace the solid liquid interface. The energy Equations (1) and (2) were re-written by replacing temperature with total enthalpy. The problem was solved numerically using the explicit finite difference method [9], where the PCM (of dimensions $0.46 \times 0.45 \times B \mathrm{~m}$ ) was divided into a number of equal thickness/size layers and Equation (4) was applied to each layer.

$H_{\mathrm{P}}^{i+1}=H_{\mathrm{P}}^{i}+\left\{\left[\Delta t \frac{k}{\Delta y} A_{\mathrm{L}}\left(T_{\mathrm{N}}-T_{\mathrm{P}}\right)\right]-\left[\Delta t \frac{k}{\Delta y} A_{\mathrm{L}}\left(T_{\mathrm{P}}-T_{\mathrm{S}}\right)\right]\right\}$

At the boundaries, $\Delta t \times Q_{\text {fridge }}$ replaced the first term in brackets in Equation (4) for the bottom layer boundary, whilst $\Delta t \times Q_{\text {evaporator }}$ replaced the second term in Equation (4) for the top layer boundary. The thermal conductivity used in Equation (4) was defined as a function of the liquid fraction $\left(L_{\mathrm{f}}\right)$ in the PCM. The liquid fraction was obtained using the appropriate expression selected from those shown below.

$L_{f}=\left\{\begin{array}{ccc}0 & \text { if } H \leq 0 \quad \text { (solid) } \\ \frac{H}{m_{\mathrm{L}} \lambda} & \text { if } 0<H<m_{\mathrm{L}} \lambda \quad \text { (mushy) } \\ 1 & \text { if } H>m_{\mathrm{L}} \lambda \quad \text { (liquid) }\end{array}\right.$

The thermal conductivity was then calculated using the appropriate condition from those shown in 6 .

$k=\left\{\begin{array}{cl}L_{\mathrm{f}} \times k_{\text {liq }}+\left(1-L_{\mathrm{f}}\right) \times k_{\mathrm{sol}} & \text { if } H \leq m_{\mathrm{L}} \lambda \\ k_{\text {liq }} & \text { if } H>m_{\mathrm{L}} \lambda\end{array}\right.$

Finally, the temperature was then determined from the enthalpy values using the relevant equation from the three relationships shown below. 
Table 2

Boundary conditions used during the freezing and melting processes.

\begin{tabular}{|c|c|c|c|c|}
\hline \multirow[b]{2}{*}{$\begin{array}{l}\text { Ambient } \\
\text { temperature }\left({ }^{\circ} \mathrm{C}\right)\end{array}$} & \multicolumn{2}{|c|}{ Freezing process } & \multicolumn{2}{|c|}{ Melting process } \\
\hline & $\begin{array}{l}Q_{\text {fridge }} \\
(W)\end{array}$ & $\begin{array}{l}Q_{\text {evaporator }}(\mathrm{W}) \\
T_{\text {evaporator }}=-10{ }^{\circ} \mathrm{C}\end{array}$ & $\begin{array}{l}Q_{\text {fridge }} \\
(\mathrm{W})\end{array}$ & $\begin{array}{l}\mathrm{Q}_{\text {evaporator }}(\mathrm{W}) \\
T_{\text {evaporator }}=0^{\circ} \mathrm{C}\end{array}$ \\
\hline 20 & 18.72 & 262 & 18.72 & 0 \\
\hline 25 & 23.80 & 246 & 23.80 & 0 \\
\hline 30 & 28.88 & 230 & 28.88 & 0 \\
\hline
\end{tabular}

$T=\left\{\begin{array}{cc}T_{\text {mel }}+\frac{H}{m_{\mathrm{L}} c p_{\text {sol }}} & \text { for } H<0 \\ T_{\text {mel }} & \text { for } 0 \leq H \leq m_{\mathrm{L}} \lambda \\ T_{\text {mel }}+\frac{H-m_{\mathrm{L}} \lambda}{m_{\mathrm{L}} c p_{\text {liq }}} & \text { for } H>m_{\mathrm{L}} \lambda\end{array}\right\}$

In order to ensure convergence, the time step $\Delta t$ and layer thickness $\Delta y$ were selected to comply with the following criteria: $\left(\Delta t / \Delta y^{2}\right)<(\rho c p / 2 k)$. The boundary conditions used for the PCM freezing and melting process simulations are shown in Table 2.

\subsection{Effect of PCM thickness on the charge and discharge rates}

The total storage capacity for the PCM modelled varied between $138 \mathrm{~kJ}$ for a $2 \mathrm{~mm}$ slab and $345 \mathrm{~kJ}$ for a $5 \mathrm{~mm}$ slab. To determine the PCM freezing and melting times with different thicknesses, a refrigerator heat load of $23.8 \mathrm{~W}$ was assumed, which corresponded to an ambient temperature of $25^{\circ} \mathrm{C}$. The compressor was assumed to be off during the melting process and to be running continuously with a cooling capacity of $246 \mathrm{~W}$ during the freezing process, which corresponded to an evaporating temperature of $-10{ }^{\circ} \mathrm{C}$. The predicted influence of PCM thickness on melting and freezing times is shown in Figs. 3 and 4 respectively.

From Fig. 3 it can be seen that the melting time increased from $101 \mathrm{~min}$ (i.e. $6060 \mathrm{~s}$ ) to $252 \mathrm{~min}$ (i.e. 15,120 s) as the PCM thickness increased from $2 \mathrm{~mm}$ to $5 \mathrm{~mm}$. In Fig. 4 , the freezing time was $13 \mathrm{~min}$ for the $2 \mathrm{~mm}$ slab and $34 \mathrm{~min}$ for the $5 \mathrm{~mm}$ slab.

\subsection{Effect of ambient temperature on the charge and discharge rate}

The effect of ambient temperature on the PCM charge and discharge rate was evaluated for a $5 \mathrm{~mm}$ PCM slab. The fridge heat load and evaporator cooling capacity for the range of ambient temperatures are listed in Table 2. Figs. 5 and 6 demonstrate the influence of ambient temperature on the PCM melting and freezing times.

In Fig. 5, the melting time decreased from $320 \mathrm{~min}$ to $208 \mathrm{~min}$ when the ambient temperature was increased from $20^{\circ} \mathrm{C}$ to $30^{\circ} \mathrm{C}$,

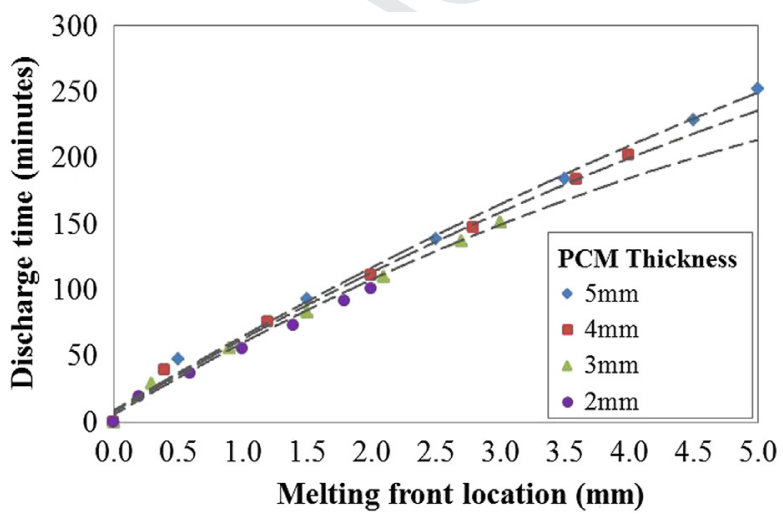

Fig. 3. Effect of thickness on the PCM melting time.

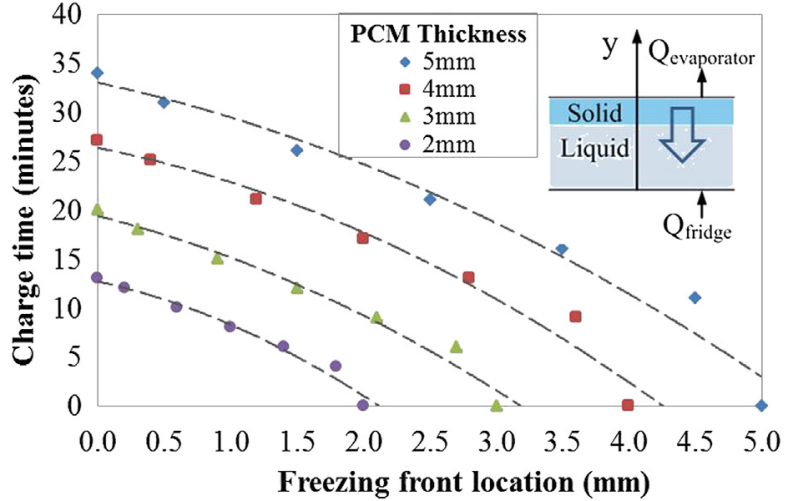

Fig. 4. Effect of thickness on the PCM freezing time.

which corresponded to a reduction of $65 \%$ in refrigerator autonomy i.e. without power supply. Fig. 6 shows that the freezing time increased slightly with ambient temperature, with an additional 7 min being needed to freeze the PCM at $30{ }^{\circ} \mathrm{C}$ ambient, as compared with $20^{\circ} \mathrm{C}$ ambient.

\subsection{Effect of evaporating temperature on the PCM freezing time}

The influence of evaporating temperature on the PCM freezing time was estimated using the cooling capacity of the $8 \mathrm{~cm}^{3}$ compressor at $-10{ }^{\circ} \mathrm{C}(262 \mathrm{~W})$ and $-15^{\circ} \mathrm{C}(213 \mathrm{~W})$ for an ambient temperature of $25{ }^{\circ} \mathrm{C}$. The analysis was performed using a $5 \mathrm{~mm}$ PCM slab. The impact of evaporating temperature on the PCM freezing time is illustrated in Fig. 7.

It was found that the freezing time increased by $26 \%$ as a result of reducing the evaporating temperature from $-10{ }^{\circ} \mathrm{C}$ to $-15^{\circ} \mathrm{C}$. The strong influence of evaporating temperature on PCM freezing time was to be expected, since the compressor COP increases linearly with evaporating temperature.

\section{Experimental evaluation of PCM freezing/melting process}

\subsection{Experimental test rig}

The experimental rig, which was designed to validate the numerical model, consisted of a prototype under-counter refrigerator (internal dimensions $0.75 \times 0.45 \times 0.46 \mathrm{~m}$ ) cooled by an external coolant system as illustrated in Fig. 8. The coolant system was used instead of a traditional vapour compression system, in order to

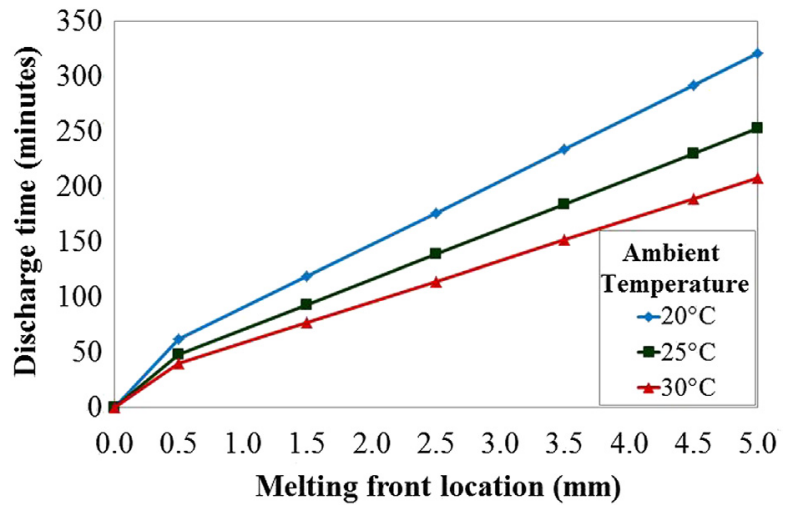

Fig. 5. Effect of ambient temperature on the PCM melting time for a $5 \mathrm{~mm}$ slab. 


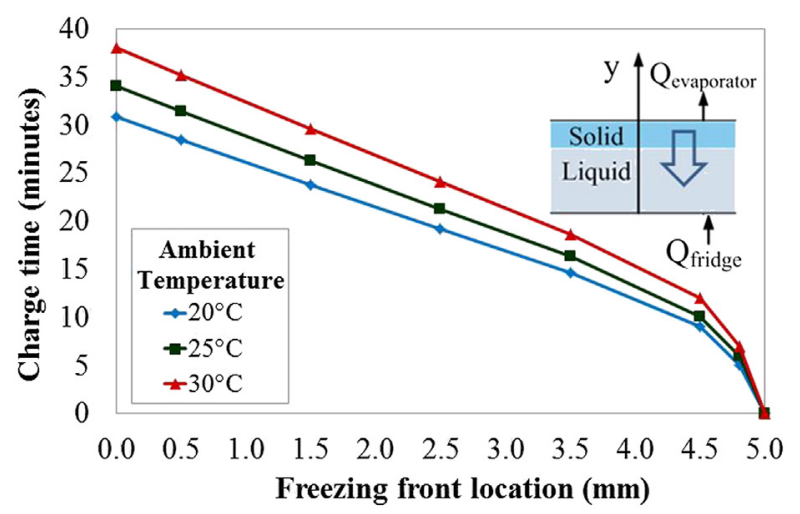

Fig. 6. Effect of ambient temperature on the PCM freezing time for a $5 \mathrm{~mm}$ slab.

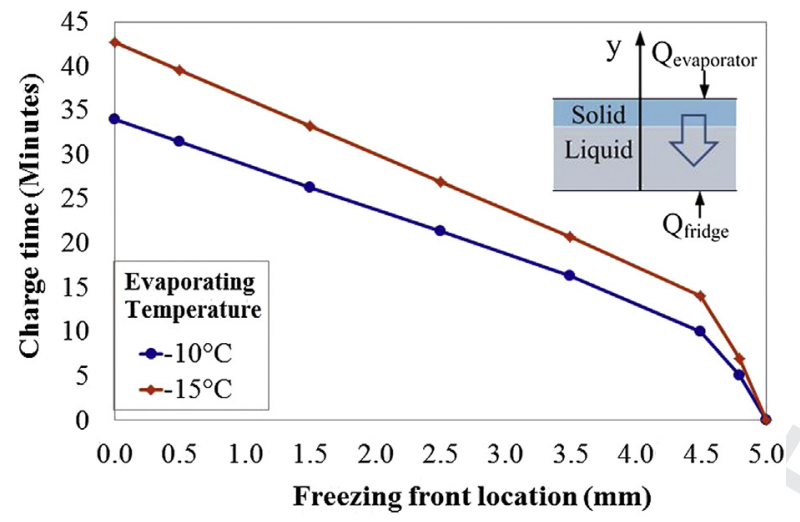

Fig. 7. Effect of evaporating temperature on the PCM freezing time.

prevent temperature cycling, thus maintaining steady state conditions within the heat exchanger throughout the experiments.

The PCM employed was $1 \mathrm{~kg}$ of pure (distilled) water (dimensions $0.45 \times 0.46 \times 0.005 \mathrm{~m}$ ). This material was selected due to its suitable phase change temperature, safety and large latent heat of fusion. The PCM container used was an open topped copper box, enclosed at the top with a heat exchanger supported by eight plastic cylinders, which ensured that the PCM thickness was consistently $5 \mathrm{~mm}$ across the whole surface area. The heat

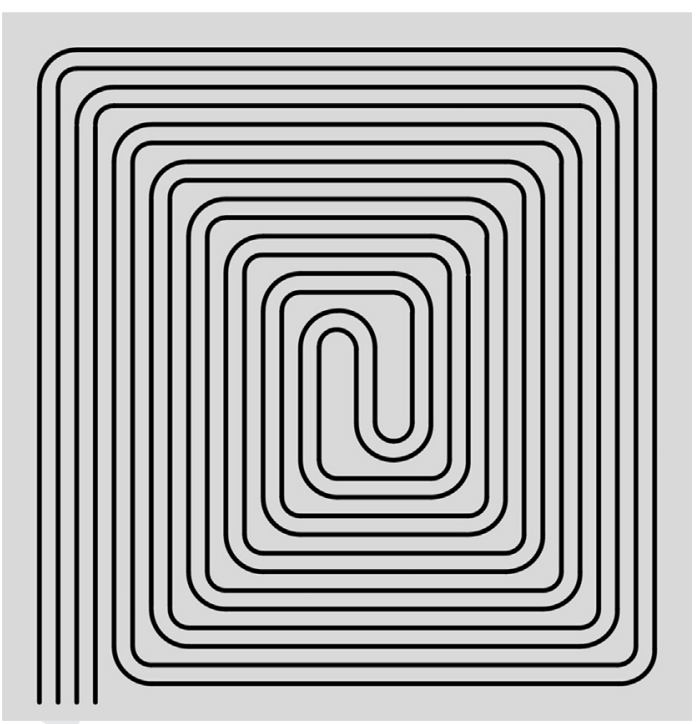

Fig. 9. Heat exchanger.

exchanger consisted of a $0.002 \mathrm{~m}$ thick copper plate with an $8.1 \mathrm{~m}$ copper tube $(0.0064 \mathrm{~m}$ external diameter) soldered to the plate surface. The tube was arranged in a spiral shape to ensure that heat transfer to the PCM was spatially uniform (see Fig. 9).

The ethylene glycol/water solution was cooled in the thermostatic controlled bath (to $-10^{\circ} \mathrm{C}$ ) and pumped through the horizontal heat exchanger, freezing the PCM beneath, which then cooled the refrigerator compartment. After exiting the heat exchanger the coolant was returned to the thermostatic bath completing the circuit. A ball valve was used to control the inlet flow to the heat exchanger. It was opened at the beginning of each PCM charge cycle and closed once the PCM temperature readings indicated that the PCM was frozen.

\subsection{Temperature measurements in PCM, coolant and refrigerator compartment}

The temperatures within the PCM, at the inlet and outlet of the heat exchanger, in the refrigerator compartment and the ambient temperature were measured with calibrated T-type thermocouples

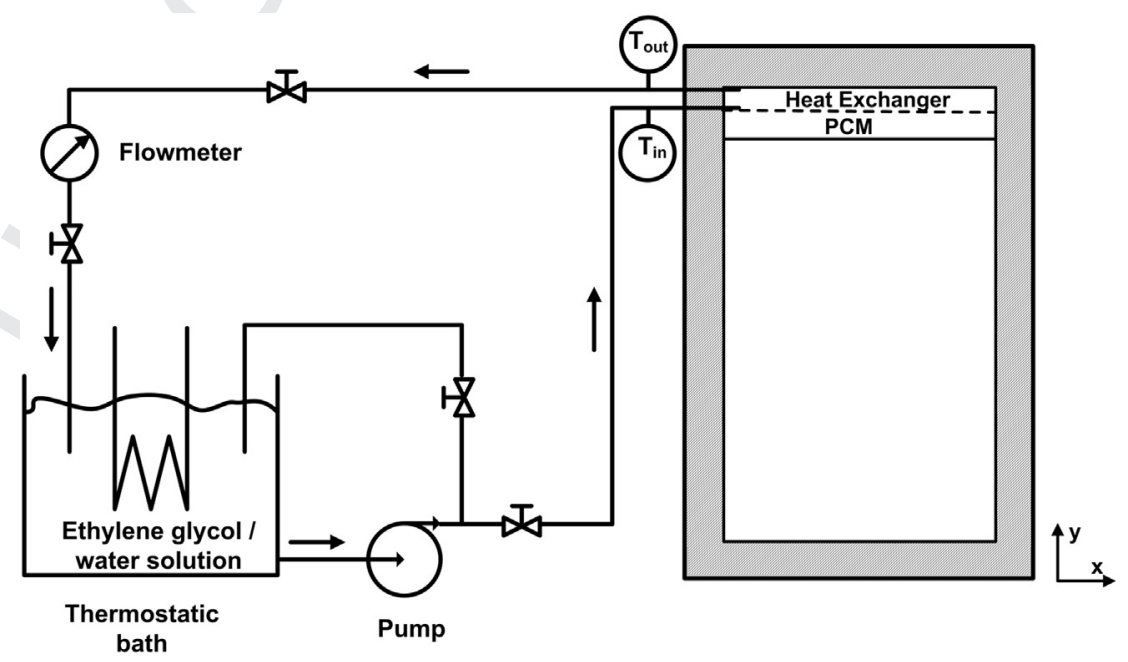

Fig. 8. Schematic of the experimental test rig. 
which were connected to two IOTech Personal Daq/56 data acquisition systems. The thermocouples were calibrated in a temperature controlled Julabo refrigerated/heating circulator bath against a platinum resistance thermocouple with an accuracy of $\pm 0.06 \mathrm{~K}$. The average uncertainty of the temperature measurements was $\pm 0.3^{\circ} \mathrm{C}$. A total of 14 thermocouples were distributed uniformly (in 2D) inside the PCM (as shown in Fig. 13). The ambient air temperature in the test room was closely controlled during the experiments to $20^{\circ} \mathrm{C}, 25^{\circ} \mathrm{C}$ and $30^{\circ} \mathrm{C}$, to an accuracy of $\pm 0.5^{\circ} \mathrm{C}$, using an air-conditioning system.

\subsection{Estimation of system cooling capacity and heat gain by the refrigerator compartment}

The cooling duty was calculated from the coolant mass flow rate and the temperature difference between the glycol inlet and outlet for the heat exchanger. The glycol mass flow rate was measured to an accuracy of $\pm 0.015 \mathrm{~kg} \mathrm{~s}^{-1}$ using a GEM turbine type volume flow meter and a Hengstler Tico 731 tachometer.

The overall heat transfer coefficient (U-value) for the refrigerator prototype was measured experimentally to determine the real cabinet heat gain from the ambient environment. A fan with a power of $21 \mathrm{~W}$ was fitted inside the refrigerator compartment, and the whole experimental rig was placed in a controlled temperature room at $22{ }^{\circ} \mathrm{C}$ until thermal equilibrium was reached. The fan power, ambient and refrigerator temperatures were averaged over a stable period of $5 \mathrm{~h}$ to calculate the $\mathrm{U}$-value of the refrigerator prototype, which was determined to be $0.61 \mathrm{~W} \mathrm{~m} \mathrm{~m}^{-2} \mathrm{~K}^{-1}$.

\section{Results and discussion}

\subsection{Comparison of predicted and measured PCM temperatures during freezing/melting cycle}

The PCM initial temperature; the estimated heat gain into the refrigerator prototype; and the cooling duty measured during the experiments, were introduced into the finite difference model described in Section 4 and used to calculate the PCM charge and discharge rate. The numerical model predictions and the experimental results were then compared. Figs. 10 and 11 show the PCM temperatures during a charge/discharge cycle predicted by the numerical method together with those for the experimental results recorded, for an ambient temperature of $20{ }^{\circ} \mathrm{C}$ and $25{ }^{\circ} \mathrm{C}$ respectively.

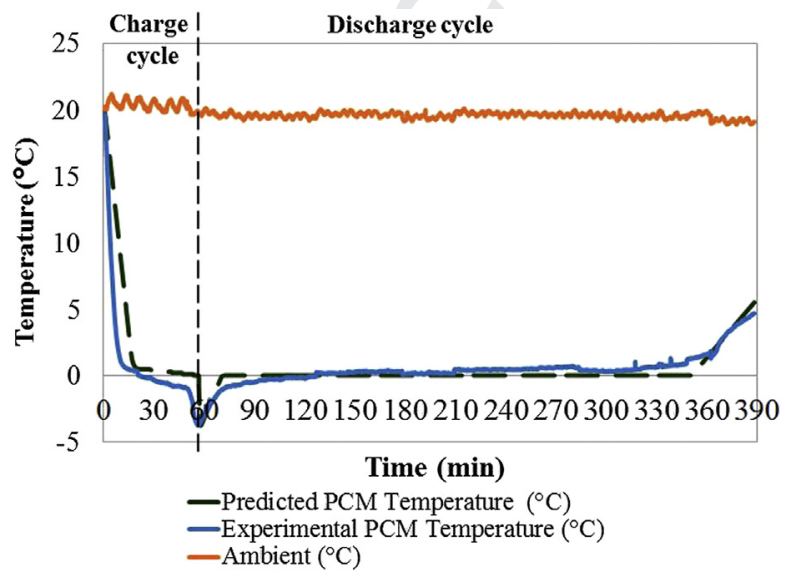

Fig. 10. $\mathrm{PCM}$ centre temperature during the charge and discharge cycle at $20^{\circ} \mathrm{C}$ ambient.

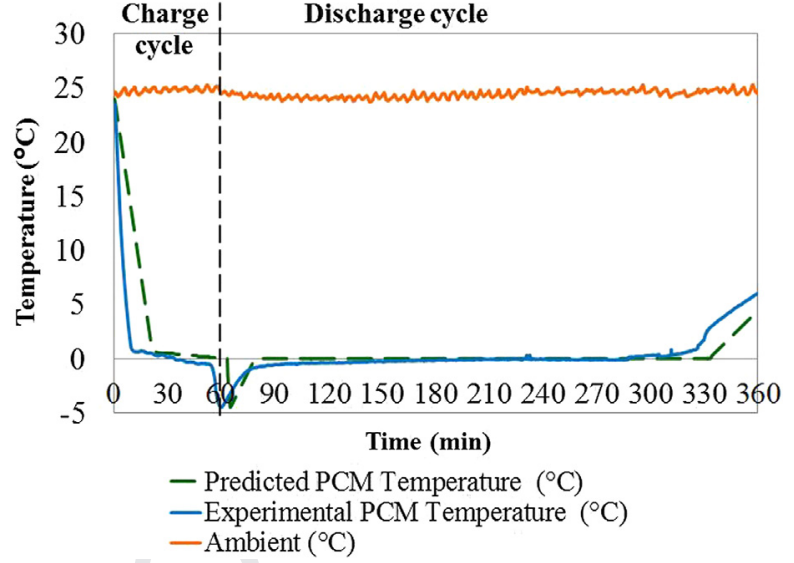

Fig. 11. PCM centre temperature during the charge and discharge cycle at $25{ }^{\circ} \mathrm{C}$ ambient.

The PCM temperatures predicted by the numerical model closely matched the temperature profile measured during the experiments as demonstrated in Figs. 10 and 11. A similar profile was obtained at $30{ }^{\circ} \mathrm{C}$ ambient. PCM melting times of $175 \mathrm{~min}(2.9 \mathrm{~h})$ and $290 \mathrm{~min}(4.8 \mathrm{~h})$ were predicted for ambient temperatures of $30{ }^{\circ} \mathrm{C}$ and $20^{\circ} \mathrm{C}$ respectively. During the PCM freezing cycle, heat was removed from the heat exchanger and the PCM. The difference between the cooling supplied and the cooling removed was approximately $40 \mathrm{~W}$. This is because there was heat gain from ambient. Taking the heat gain into consideration the error between cooling supplied and cooling removed was only approximately 7.5\% on average. There was a slight discrepancy in the PCM temperatures at the beginning of freezing cycle as the sensible heat was predicted to be removed from the PCM more slowly by the numerical model than that measured in the experimental rig. It is believed that the small difference between the model predicted results and the experimental data is due to the fact that the model neglected the convection currents inside the PCM (while in liquid state), which enhanced heat transfer and therefore resulted in a faster freezing rate during the first part of the cycle. Table 3 shows the average difference between the predicted and experimental results for total freezing and melting times.

As can be seen in Table 3 there was a good agreement between the numerical model prediction and experimentally measured PCM freezing and melting times.

Overall, the experimental results indicated that the integration of a $5 \mathrm{~mm}$ PCM slab into the refrigerator would allow $37^{5 \mathrm{~h} \text { of }}$ continuous operation without power supply depending on the ambient conditions.

\subsection{Experimentally measured data for PCM during charging}

\subsubsection{Temperature distribution in the PCM}

The experimental results showing the glycol bath, coil inlet and outlet temperatures and the PCM centre temperature measured during the freezing cycle are presented in Fig. 12. The PCM temperatures at a range of locations in the PCM are shown in Fig. 13.

As can be seen in Fig. 12 the heat exchanger coil outlet temperature decreased rapidly during the first $10 \mathrm{~min}$ as sensible heat was removed from the PCM. The steep increase in the coil outlet temperature between 9.7 and 11.3 min marked the beginning of the phase change from liquid water to solid ice. Thereafter, the coil outlet temperature decreased slowly until the PCM was completely frozen i.e. fully charged. Of the 14 thermocouples placed inside the PCM, 12 were distributed at a height of $3 \mathrm{~mm}$, whilst the remaining 
Table 3

Comparison between model predicted and experimentally measured freezing and melting times at different ambient temperatures.

\begin{tabular}{|c|c|c|c|c|c|c|c|c|}
\hline \multirow{2}{*}{$\begin{array}{l}\text { Ambient } \\
\text { temperature }\left({ }^{\circ} \mathrm{C}\right)\end{array}$} & \multirow{2}{*}{$\begin{array}{l}\text { Measured } \\
\text { cooling duty (W) }\end{array}$} & \multirow{2}{*}{$\begin{array}{l}\text { Measured } \\
\text { heat gain }(W)\end{array}$} & \multicolumn{2}{|c|}{ Freezing time (min) } & \multicolumn{2}{|c|}{ Melting time (min) } & \multirow{2}{*}{$\begin{array}{l}\text { Freezing } \\
\text { error (\%) }\end{array}$} & \multirow{2}{*}{$\begin{array}{l}\text { Melting } \\
\text { error (\%) }\end{array}$} \\
\hline & & & Predicted & Measured & Predicted & Measured & & \\
\hline 20 & 191 & 21.3 & 57 & 57 & 294 & 290 & 0.3 & -1.5 \\
\hline 25 & 220 & 27.1 & 54 & 55 & 237 & 243 & 1.2 & 2.3 \\
\hline
\end{tabular}

two were placed at the PCM centre (thermocouples 8 and 9) and positioned at heights of 1 and $4 \mathrm{~mm}$ respectively. Fig. 13 shows that the PCM centre was the last region to freeze (thermocouple 8). At this location the temperature remained constant as the latent heat was released and suddenly decreased after 55 min indicating that the ice crystallization had reached the PCM centre. The temperature distribution within the PCM was largely uniform. A large portion of the PCM volume (80\%) was frozen after $35 \mathrm{~min}$; this was apparent from the abrupt temperature decrease below $0{ }^{\circ} \mathrm{C}$ for $40 \%$ of the thermocouples (see Fig. 13) as sensible heat began to be removed from the ice.

\subsubsection{Supercooling effect}

Supercooling occurs when the temperature of a liquid is lowered below its freezing point without it becoming a solid [17]. It is seen in Fig. 13, that the water PCM was supercooled to $-1.5 /-2{ }^{\circ} \mathrm{C}$ before the ice formation process started. The crystallization process of the PCM material involves a combination of nucleation and growth of ice crystals within a crystalline structure. The effect of subcooling makes it necessary to reduce the temperature below the phase change temperature to start crystallization and to release the latent heat stored in the material. If nucleation does not happen,

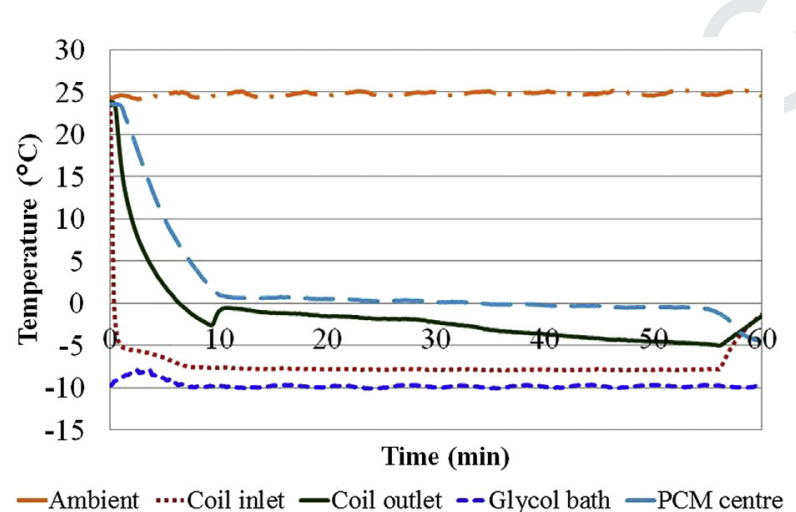

Fig. 12. Freezing cycle temperatures.

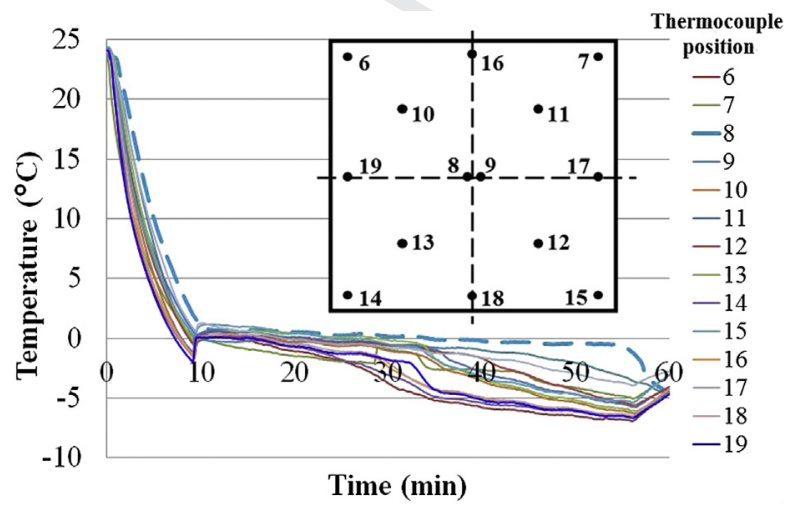

Fig. 13. Temperature at various locations within the PCM. the latent heat is not released, and the material only stores sensible heat. It is seen in Fig. 13, that the water PCM was supercooled to $-2{ }^{\circ} \mathrm{C}$ during $2.3 \mathrm{~min}$ before the solidification process started. At a temperature of $-2{ }^{\circ} \mathrm{C}, 8 \mathrm{~kJ} \mathrm{~kg}^{-1}$ of sensible heat was lost due to subcooling, which is much less than the latent heat release of $333 \mathrm{~kJ} \mathrm{~kg}^{-1}$ during crystallization. Because the heat released during solidification/crystallization is larger than the heat lost due to supercooling, the temperature inside the PCM rises to the melting temperature and remains there until the phase change is completed.

\section{Conclusions}

The compressor performance analysis demonstrated that in general, larger compressors are more efficient, with isentropic efficiency increasing by $50 \%$ as the displacement increased from 4 to $8 \mathrm{~cm}^{3}$. An energy reduction of $19.5 \%$ was predicted for the static refrigerator by replacing the $4 \mathrm{~cm}^{3}$ with an $8 \mathrm{~cm}^{3}$ compressor, for continuous operation. However, in a conventional refrigerator a larger compressor would result in more on/off cycling reducing the efficiency. The method proposed to exploit the superior performance i.e. efficiency, of larger compressors is to accumulate their excess cooling capacity in a PCM increasing the refrigerator autonomy i.e. off-cycle period, without power supply, from a few minutes to several hours. The PCM heat release and storage rate model developed indicated that the melting and freezing time increased proportionally with PCM thickness. Employing thin PCM slabs $(\leq 5 \mathrm{~mm})$ ensured that the net volume of the compartment was not reduced substantially, while moderate length compressor run times (i.e. on-cycle times) were obtained. Both the numerical simulation and the experimental results demonstrated that the integration of a $5 \mathrm{~mm}$ PCM slab into the refrigerator allowed between 3 and 5 h of continuous autonomous operation i.e. without power supply, depending on thermal load. The numerical model, which predicted the PCM charge and discharge time was found to be in good agreement with the experimental results with the majority of the experiments showing a margin of error between predicted and experimental values of $<5 \%$, and the remainder within $10 \%$. The combination of a large displacement compressor and a thin PCM is a novel design approach that has the potential to significantly enhance refrigerator efficiency.

\section{Acknowledgements}

The financial support of the Engineering and Physical Sciences Research Council (EPSRC) and Adande Refrigeration is gratefully acknowledged.

\section{References}

[1] S.F. Pearson, 17th Informatory Note on Refrigerating Technologies: How to Improve Energy Efficiency in Refrigerating Equipment, International Institute of Refrigeration, 2003.

[2] D. Coulomb, Refrigeration and cold chain serving the global food industry and creating a better future: two key IIR challenges for improved health and environment, Trends Food Sci. Technol. 19 (2008) 413-417.

[3] P. Manini, G. Pastore, P. Di Gregorio, Vacuum Insulated Panels (VIPs) Technology: A Viable Route to Reduce Energy Consumption in Domestic, 
Industrial and Civil Applications, in: EURO Cooling \& Heating, Centro Studi Galileo, 2003 (Online). Available: http://www.eurocooling.com/public_html/ articlesaesgetters.htm (accessed 15.03.11).

[4] D.-Y. Liu, W.-R. Chang, J.-Y. Lin, Performance comparison with effect of door opening on variable and fixed frequency refrigerators/freezers, Appl. Therm. Eng. 24 (2004) 2281-2292.

[5] R. Saidur, H.H. Masjuki, I.A. Choudhury, Role of ambient temperature, door opening, thermostat setting position and their combined effect on refrigerator/ freezer energy consumption, Energy Convers. Manage. 43 (2002) 845-854.

[6] E. Björk, B. Palm, Refrigerant mass charge distribution in a domestic refrigerator, part I: transient conditions, Appl. Therm. Eng. 26 (2006) 829-837.

[7] P.K. Bansal, Developing new test procedures for domestic refrigerators: harmonisation issues and future R \& D needs - a review, Int. J. Refrig. 26 (2003) 735-748.

[8] K. Azzouz, D. Leducq, D. Gobin, Enhancing the performance of household refrigerators with latent heat storage: an experimental investigation, Int. J. Refrig. 32 (2009) 1634-1644.

[9] V. Alexiades, A.D. Solomon, Mathematical Modelling of Melting and Freezing Processes, Hemisphere Publishing Corporation, Washington, 1993.

[10] ASHRAE Refrigeration Handbook, 2006.

[11] (Online). Available:, Danfoss RS +3 Compressor and Condensing Unit Selection Tool, 3.6 ed, Danfoss, 1998 http://www.danfoss.com/BusinessAreas/
RefrigerationAndAirConditioning/Product+Selection+Tools+Details/RSplus3. htm.

[12] P. Domanski, Theoretical Evaluation of the Vapor Compression Cycle with a Liquid-line/suction-line Heat Exchanger, Economizer and Ejector, 1995. NISTIR 5606.

[13] Coolpack Software, Denmark Technical University, Department of Mechanical Engineering, 1998 (Online). Available: http://www.et.web.mek.dtu.dk/Coolpack/ UK/download.html.

[14] C. Marques, J.A. Evans, G. Davies, G. Maidment, I. Wood, Novel design and performance of domestic refrigerators, in: 1st IIR Conference on Sustainability and the Cold Chain. Cambridge, UK, 2010.

[15] EN 153:2006, Methods of Measuring the Energy Consumption of Electric Mains Operated Household Refrigerators, Frozen Food Storage Cabinets, Food Freezers and Their Combinations, Together with Associated Characteristics, European Committee for Standardization, 2006.

[16] P. Verma, Varun, S.K. Singal, Review of mathematical modelling on latent heat thermal energy storage systems using phase-change material, Renew. Sustain. Energy Rev. 12 (2008) 999-1031.

[17] H. Mehling, L.F. Cabeza, Heat and Cold Storage with PCM: An up to Date Introduction into Basics and Applications (Heat and Mass Transfer), Springer, Berlin, 2008. 